\title{
Occupation and life satisfaction among individuals with mental illness: the mediation role of self-reported psychophysiological health
}

\author{
Alexandre Granjard \\ , Marko Mihailovic Equal first author, 1,4,5,6 , Clara Amato ${ }^{\text {1,7 }}$, Maryam Kazemitabar ${ }^{\text {8, } 9}$, \\ Franco Lucchese $^{7,10}$, Christian Jacobsson ${ }^{2}$, Nobuhiko Kijima ${ }^{11,12}$, Danilo Garcia ${ }^{\text {Corresp. 1, 2, 4, 13,14 }}$ \\ ${ }^{1}$ Blekinge Centre of Competence, Region Blekinge, Karlskrona, Sweden \\ 2 Department of Psychology, University of Gothenburg, Gothenburg, Sweden \\ 3 Promotion of Health and Innovation (PHI), Network for Well-Being, Vallauris, France \\ 4 Centre for Ethics, Law and Mental Health (CELAM), University of Gothenburg, Gothenburg, Sweden \\ 5 Department of Psychiatry and Behavioral Sciences, Northwestern University, Chicago, Illinois, United States \\ 6 Promotion of Health and Innovation (PHI), Network for Well-Being, Chicago, United States \\ 7 Promotion of Health and Innovation (PHI), Network for Well-Being, Rome, Italy \\ 8 Department of Psychology, University of Teheran, Teheran, Iran \\ 9 Promotion of Health and Innovation (PHI), Network for Well-Being, Teheran, Iran \\ 10 Department of Dynamic and Clinical Psychology, University of Rome "La Sapienza", Rome, Italy \\ 11 Faculty of Business and Commerce, Keio University, Tokyo, Japan \\ 12 Promotion of Health and Innovation (PHI), Network for Well-Being, Tokyo, Japan \\ 13 Department of Behavioral Sciences and Learning, Linköping University, Linköping, Sweden \\ 14 Promotion of Health and Innovation (PHI), Network for Well-Being, Karlskrona, Sweden \\ Corresponding Authors: Alexandre Granjard, Danilo Garcia \\ Email address: alexandre.granjard.beolet@gmail.com, danilo.garcia@icloud.com
}

\section{Background}

Unemployment can diminish physical, psychological and social health. In this context, research shows that people with mental illness have even more difficulties finding occupation. Thus, some countries, such as Sweden, strive after creating job opportunities for this specific group. We investigated the effect of having an occupation on life satisfaction among individuals with mental illness and whether selfreported physical and psychological health mediated the relationship between being (un)employed and life satisfaction.

\section{Method}

Two-hundred eighty-seven individuals (148 males, 134 females, and 5 missing information) with mental illness, who received support and services from Swedish Municipalities in Blekinge, self-reported occupation, life satisfaction, and physical and psychological health.

\section{Results}

Participants who reported having an occupation reported also significantly higher levels of life satisfaction, physical health, and psychological health compared to those without occupation.

Nevertheless, these differences were rather small $\left(E \mathrm{ta}^{2}<.06\right)$. Moreover, the indirect effect of having an Peerj reviewing PDF | (2020:10:54421:1:1:NEW 31 Dec 2020) 
occupation on life satisfaction through physical and psychological health was significant. Finally, the total indirect effect of physical and psychological health (i.e., psychophysiological health) accounted for $53 \%$ of the total effect of having an occupation on life satisfaction.

\section{Conclusion}

For individuals with mental illness there seems to be an almost equal importance of indirect and direct effects of having an occupation on their levels of life satisfaction. More specifically, while there are differences in life satisfaction within this population in relation to having an occupation, having an occupation leads to the sense of good psychophysiological health, which in turn helps individuals with mental illness to feel satisfied with their lives. 


\section{Background}

34 Unemployment can diminish physical, psychological and social health. In this context, research shows that people with mental illness have even more difficulties finding occupation. Thus, some countries, such as Sweden, strive after creating job opportunities for this specific group. We investigated the effect of having an occupation on life satisfaction among individuals with mental illness and whether self-reported physical and psychological health mediated the relationship between being (un)employed and life satisfaction.

\section{Method}

Two-hundred eighty-seven individuals (148 males, 134 females, and 5 missing information) with mental illness, who received support and services from Swedish Municipalities in Blekinge, selfreported occupation, life satisfaction, and physical and psychological health.

\section{Results}

45 Participants who reported having an occupation reported also significantly higher levels of life satisfaction, physical health, and psychological health compared to those without occupation. Nevertheless, these differences were rather small $\left(E t a^{2}<.06\right)$. Moreover, the indirect effect of having an occupation on life satisfaction through physical and psychological health was significant. Finally, the total indirect effect of physical and psychological health (i.e., psychophysiological health) accounted for $53 \%$ of the total effect of having an occupation on life 51 satisfaction.

\section{Conclusion}

53 For individuals with mental illness there seems to be an almost equal importance of indirect and direct effects of having an occupation on their levels of life satisfaction. More specifically, while there are differences in life satisfaction within this population in relation to having an occupation, having an occupation leads to the sense of good psychophysiological health, which in turn helps individuals with mental illness to feel satisfied with their lives.

Keywords: Life Satisfaction, Self-reported Health, Mental Illness, (Un)Employment, Occupation, Psychophysiological Health. 


\section{Introduction}

65 Unemployment can lead to, among other things, diminished social status, financial debt, reduced self-esteem, and feelings of guilt. Most importantly, unemployment is significantly associated with

67 psychiatric problems and approximately 37\% higher risk of suicide (Milner, Page \& LaMontagne,

68 2014). For this reason, there are many interventions aimed to help unemployed individuals to

69 preserve their physical and psychological health during this period (e.g., Cloninger, Granjard, 70 Lester, Lindskär, Rosenberg, Cloninger \& Garcia, 2020). Health, however, encompasses also 71 positive outcomes, such as satisfaction with one's life, which is a good proxy for people's well72 being (Diener, Lucas \& Oishi, 2018). In this context, the effect of having an occupation has 73 probably a greater effect on individuals who already have psychiatric problems and who, therefore, 74 have greater difficulty in finding, getting and maintaining a job. Indeed, some countries, such as 75 Sweden, create policies that promote job opportunities for this specific group 76 (https://sweden.se/society/swedens-disability-policy/).

Employment appears to be an important factor in the recovery of individuals with mental illness (e.g., major depression, bipolar disorder, and schizophrenia) (Dunn, Wewiorski \& Rogers, 2008). Previous research, for example, shows that having an occupation leads to community and social integration, which is a vital part for recovery and rehabilitation; because it enables individuals to live their own life and to perform desired social activities. In other words, by having an occupation a person moves out of their self-stigmatized role and protective environments,

83 towards community and social integration (Bond, Sayers, Rollins, Rapp \& Zipple, 2004).

84 Nevertheless, society often accepts and assumes a non-working lifestyle for people with mental

85 illness. This might lead to further stigmatization and marginalization, thus, affecting their health 86 and diminishing life satisfaction. Accordingly, only $10 \%$ to $20 \%$ of people with mental illness are 
87 actually employed in Europe (Marwaha, Jonson, Bebbington, Angermeyer, Brugha, Azorin, 88 Kilian, Hansen \& Toumi, 2007). This level of employment among individuals with mental illness

89 appears to be a global trend. In the USA, for example, only $10-15 \%$ of this population is employed.

90 Independently of which country is in focus, research shows that being employed or having an

91 occupation is associated with reduced psychological distress and higher quality of life (Murphy \&

92 Athanasou, 1999). That being said, in Sweden, as much as 30\% of people with mental illness are

93 actually employed. Still, 70\% are unemployed and more marginalized compared to people in other

94 disability groups. Moreover, only $8 \%$ have paid employment and $60 \%$ have no occupations at all

95 (National Board of Health and Welfare, 1998). In this context, having an occupation is seen as a

96 critical milestone for physical and psychological recovery, as well as an important factor for life

97 satisfaction.

In short, inactivity and loss of productive years are associated to mental illness. What is more, individuals with mental illness become discouraged when they fail finding or maintaining a job. Indeed, unemployment alone can lead to deterioration in physical and psychological health even among previously healthy individuals. This effect is more accentuated for those individuals who had mental illness to begin with (Corrigan \& McCracken, 2005) and who often present higher prevalence of health-related risks (Blomqvist, Ivarsson, Carlsson, Sandgren \& Jormfeldt, 2018; Lundström, Ahlström, Jormfeldt, Eriksson \& Skärsäter, 2017). Having an occupation is expected to help to reintegrate individuals with mental illness and disabilities into their communities, because having an occupation decreases self-stigma and increases the sense of being physically and psychologically healthy. For these reasons, improving vocational rehabilitation services has

108 become a priority for the promotion of quality of life, life satisfaction, and health per se (Bond,

109 Sayers, Rollins, Rapp \& Zipple, 2004). Nevertheless, the question is if having an occupation is 
110 related to the physical and psychological health of individuals with mental illness or if having an

111 occupation per se increases life satisfaction? Many policies in this regard are actually based on the

112 assumption that having an occupation directly leads to both health and life satisfaction, despite the

113 fact that the association between health and life satisfaction is not straightforward (Rohrer \&

114 Lucas, 2020). For instance, there are many confounding factors that affect both health and life

115 satisfaction (Rohrer \& Lucas, 2020). To the best of our knowledge, however, no studies have

116 addressed these relationships within a Swedish population with mental illness.

\section{The Present Study}

118 Our aim was to investigate the effect of having an occupation on self-reported life satisfaction

119 among Swedish individuals diagnosed with mental illness who receive support and care from the

120 Municipalities. We also investigated whether self-reported physical and psychological health

121 mediated the relationship between being employed and life satisfaction within this population.

122 Our specific hypotheses were:

123 Hypothesis 1: Individuals with mental illness with an occupation are more satisfied with their

124 lives compared to those who do not have an occupation.

125 Hypothesis 2: Individuals with mental illness with an occupation perceive themselves as healthier,

126 both physically and psychologically, compared to those who do not have an occupation.

127 Hypothesis 3: Physical and psychological health mediate the relationship between having an 128 occupation and life satisfaction among individuals with mental illness.

\section{Method}

\section{Ethical Statement}

131 The study was performed in accordance with the ethical standards of the 1964 Helsinki declaration

132 and its later amendments. Participants were provided with the aims of the study, that participation 
133 was anonymous and voluntary, that they had the opportunity to ask questions, and that they were

134 free to withdraw at any time without giving a reason and without cost or any repercussions

135 regarding the services, care or support they received from the Municipalities. Verbal consent was

136 obtained and the study was approved by the Swedish Ethical Review Authority (Dnr. 2017/305).

\section{Participants and Procedure}

138 The present study was conducted in the fall of 2017 at the Blekinge Centre of Competence, the 139 research and development unit of Region Blekinge, Sweden. The five Blekinge Municipalities

140 were involved in the study: Sölvesborg, Olofström, Karlshamn, Ronneby, and Karlskrona. All 621

141 individuals between 18-65 years of age who received support ${ }^{1}$ due to mental illness in each of the

142 five municipalities in Blekinge were contacted. The staff working closest to the clients were the

143 ones responsible for the exclusion procedure. A total of 146 individuals were excluded from the

144 study because they suffered from dementia or were using drugs at the time the survey was

145 distributed. Out of those 475 eligible to participate, 62 chose to not participate in the study, 126

146 did not respond to all survey questions, and four of them didn't indicate if they had a job or not,

147 and were therefore excluded from the analyses. That is, the final sample represented roughly $60 \%$

148 of those eligible to participate: 287 individuals (148 males, 134 females, and 5 missing) with a

149 mean age of 43.46 years $(S D=13.32)$. About $3.5 \%$ of the participants did not finish primary

150 school, $23.7 \%$ finished primary school, $52.3 \%$ had a high-school degree, $12.2 \%$ had higher

151 education and $8.3 \%$ had other type of education. Most of the participants were single (76.3\%) and

152 lived in their own accommodation (74.6\%) and only a few of them reported living in an institution

${ }^{1}$ The support includes: help with everyday finances, help with daily shores, transport, support when contacting authorities, help taking social contact, support seeking job or occupation, and help with lifestyle habits (https://sweden.se/society/swedens-disability-policy/). 
153 for individuals with mental illness (16.4\%). A total of 112 of the participants reported not having

154 any occupation, whereas 171 reported having an occupation.

\section{Measures}

156 Life Satisfaction. We used the Swedish version (Garcia \& Siddiqui, 2009) of the Satisfaction with

157 Life Scale (Diener, Emmons, Larsen \& Griffin, 1985), which comprises 5 items (example item is:

158 "In most ways my life is close to my ideal") that are rated on a 7-point Likert scale ( $1=$ strongly

159 disagree, 7 = strongly agree). The life satisfaction score was computed as the sum score of the 5

160 items divided by 5. Consistent with previous findings with the original English version (e.g.,

161 Diener, Inglehart \& Tay, 2013), the Swedish version showed good internal consistency in the

162 present study $(\alpha=.86)$.

163 Occupation. Participants were asked to indicate if they had an occupation or not (yes/no).

164 A total of 112 of the participants reported not having any occupation, whereas 171 reported having 165 an occupation.

166 Physical and Psychological Health. Health was assessed with a 4-point Likert scale $(1=$

167 bad, 4 = excellent) and two single items: "How would you rate your physical health in general?"

168 and "How would you rate your mental health, in general?". The overall self-reported physical

169 health of the sample was $M=2.30(S D=.84)$ and the overall self-reported psychological health

170 was $M=2.26(S D=.80)$.

\section{Statistical Treatment}

172 We only used the responses of those individuals who answered to all variables included in the

173 analyses $(n=260)$. In order to test Hypotheses 1 and 2, an Analysis of Variance (ANOVA) was

174 performed using occupation as the independent factor and self-reported life satisfaction, physical

175 health, and psychological health, as the dependent variables. In order to test hypothesis 3, we used 
176 Preacher and Hayes' (2008) procedure to extrapolate estimates of direct and indirect effects. In

177 presence of a multiple mediation model, this procedure is particularly recommended because it

178 allows researchers to determine not only whether an overall indirect effect exists, but also to

179 compare the specific indirect effect of one mediator in the presence of other mediators in the model

180 (Preacher \& Hayes, 2008). As recommended, we ran the multiple mediation model using

181 bootstrapping (i.e., a nonparametric resampling procedure; in our case, 5.000 resamples) with 95\%

182 confidence intervals (CIs). All analyses were conducted in IBM SPSS version 24.

Results

184 Differences in Self-reported Life Satisfaction and Psychophysiological Health

185 Regarding self-reported life satisfaction, the analysis of variance revealed a significant difference

186 in self-reported life satisfaction $\left(F=8.162, p<.01 ; E t a^{2}=.031\right)$ between individuals who reported

187 having an occupation $(M=3.60)$ compared to those without occupation $(M=3.07)$. In addition,

188 self-reported physical health was significantly $\left(F=7.481, p<.01 ; E_{t a}^{2}=.028\right)$ higher among

189 individuals with an occupation $(M=2.42)$ compared to those without occupation $(M=2.14)$. As

190 expected, self-reported psychological health was significantly $\left(F=5.353, p<.05 ; E_{t a}^{2}=.020\right)$

191 higher among individuals with an occupation $(M=2.34)$ compared to those without one $(M=$

192 2.11). Nevertheless, these differences were rather small—all with an $E t a^{2}<.06$.

193 The Mediational Effect of Self-reported Psychophysiological Health on the Relationship

194 between Occupation Status and Self-reported Life Satisfaction

195 The mediational model was significant $\left(F_{(3,256)}=35.90, p<.001, R^{2}=.54\right.$, Adj. $\left.R^{2}=.30\right)$. More

196 specifically, the results showed that both mediators, self-reported physical $(\beta=.40 ; p<.001)$ and

197 psychological health $(\beta=.70 ; p<.001)$, were significantly positively associated to life satisfaction.

198 In addition, the total effect of occupation on self-reported life satisfaction was positive and 
199 significant (total effect $=.53$ with BCa $95 \%$ CI of .16 to .88 ) and the total indirect effect of having

200 an occupation on self-reported life satisfaction was also significant (indirect effect $=.28$, with BCa

$20195 \%$ CI of .09 to .49). Moreover, the indirect effects of having an occupation on life satisfaction

202 both through physical health (indirect effect $=.11$, with $\mathrm{BCa} 95 \% \mathrm{CI}$ of .03 to .23) and

203 psychological health (indirect effect $=.16$, with BCa 95\% CI of .03 to .32) were significant. The

204 contrast among the two indirect effects was non-significant, thus, indicating that the magnitude of 205 the mediators' effects on self-reported life satisfaction was equal. In other words, the two 206 mediators contributed equally to the effect of having an occupation on self-reported life 207 satisfaction. Finally, the total indirect effect of physical and psychological health (i.e., 208 psychophysiological health) accounted for 53\% of the total effect of having an occupation on life 209 satisfaction, thus, suggesting an almost equal importance of indirect and direct effects. See Table 2101 and Figure 1 for the details.

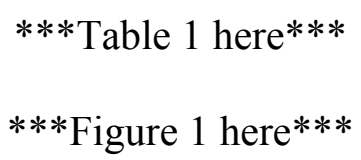

\section{Discussion}

We investigated how having an occupation is related to self-reported physical and psychological health and, in turn, to life satisfaction among individuals with mental illness who receive care and support from Municipalities in Blekinge, Sweden. Our results showed that individuals who have an occupation (vs. those who do not have one) reported being more satisfied with their lives, and perceived themselves as being in a better physical condition (i.e., physical health) and having a better mental health (i.e., psychological health). In turn, this positive perception of themselves increased a more general feeling of satisfaction with life. 

chances to find employment and making self-directed choices with regard to a healthy life style (Lundström, Jormfeldt, Hedman Ahlström \& Skärsäter, 2019). Indeed, our cross-sectional design does not allow us to scrutinize causal inference (see Rohrer \& Lucas, 2020). Moreover, the differences within this population, between individuals with an occupation and those without one, illness, who struggle to have a steady stream of income and to secure their basic human needs, such as, housing (Bond, Sayers, Rollins, Rapp \& Zipple, 2004; Henwood, Derejko, Couture \& Padgett, 2015). Indeed, being employed and having an income might provide this population with an opportunity to access better quality of life, more stable housing, and also give them a sense of personal, emotional and financial security and safety, which in turn might influence overall wellbeing (Dunn, Wewiorski \& Rogers, 2008; Henwood, Derejko, Couture \& Padgett, 2015). Furthermore, employment supports individuals with mental illness to meet needs such as social connectedness and self-esteem, which particularly improves their perception of their own psychological health (Dunn, Wewiorski \& Rogers, 2008). 
244 Rapp \& Zipple, 2004). This might help individuals with mental illness to meet the essential human

245 need of being part of a larger community (Henwood, Derejko, Couture \& Padgett, 2015). This

246 population struggle with social inclusion and acceptance due to a widely present prejudice and

247 discrimination towards individuals with mental illness (Bond, Sayers, Rollins, Rapp \& Zipple,

248 2004). These negative social factors contribute to developing a sense of isolation and loneliness

249 that ultimately lead to negative emotions such as anxiety and depression followed by deterioration

250 of overall mental and psychological health (Murphy \& Athanasou, 1999). In contrast, the sense

251 of social belongingness and community connectedness instils hope and love, which positively

252 influences their perception of psychological health and ultimately, as shown here, leading to

253 overall life satisfaction (Dunn, Wewiorski \& Rogers, 2008; Bond, Sayers, Rollins, Rapp \& Zipple, 254 2004).

Nevertheless, individuals with mental illness have difficulties with self-acceptance, due 256 to the nature of their illness (Dunn, Wewiorski \& Rogers, 2008) and the social hindrances they 257 face, such as, stigma, prejudice, and discrimination (Bond, Sayers, Rollins, Rapp \& Zipple, 2004). Indeed, most humans benefit from feeling respected, accepted, and valued by and being in the 259 service of others (Roberts, Harms, Caspi \& Moffitt, 2007; Cloninger, 2004). In short, as other studies show, employment might provide this population with a sense of contribution and value

261 and even self-acceptance (Dunn, Wewiorski \& Rogers, 2008) and also a sense of personal 262 achievement including respect from others, recognition, attention, self-efficacy and self-esteem 263 (Dunn, Wewiorski \& Rogers, 2008; Bond, Sayers, Rollins, Rapp \& Zipple, 2004). Thus, 264 individuals with mental illness who are employed are likely to increase their own trust on their 265 capabilities (self-efficacy), to feel valued (self-esteem), and to have a positive outlook about their 266 personal as well as professional future. Here however, we showed that having an occupation might 
267 not only improve their material life (e.g., income), their social life, and their trust in their own

268 capacity; but also that it is positively related to their own perception about their physical and

269 psychological health, which in turn is positively related to their life satisfaction.

270

That all being said, besides the limitations detailed above, our study had others caveats.

271 Mainly, the question of selection bias. Since the selection of participants was done by the staff

272 working closest to them, proper randomization was definitely not achieved. In other words, even

273 if we had a modest participation in our study (i.e., about $45.6 \%$ of all 621 individuals between 18 -

27465 years of age who received psychiatric support by the public services in Blekinge), those who

275 participated might not be representative for the population of individuals with mental illness.

276 Moreover, we did not include gender, age or education as covariates in the relationship between

277 having an occupation and self-reported life satisfaction and psychophysiological health. Thus,

278 future studies need to take this into consideration. After all, the relationship between health and

279 the different components of subjective well-being (e.g., life satisfaction) is complex (Rohrer \& 280 Lucas, 2020).

\section{Conclusions}

282 Individuals with mental illness who are employed, compared to those who are unemployed, 283 reported slightly higher levels of overall life satisfaction and psychophysiological health. More 284 importantly, the mechanism underlying the relationship between having an occupation and life 285 satisfaction implies that having an occupation enhances individuals' perception of their own 286 physical and psychological health, which in turn might increase their satisfaction with life. The 287 causal effect, however, is still not clear. It is possible that individuals who perceive themselves as 288 having better health are the ones who are able to find and keep a job, which in turn, leads to life 289 satisfaction. Moreover, there are many possible underlying causes to both psychological and 
290 physical health and life satisfaction that are difficult to control for (cf. Rohrer \& Lucas, 2020).

291 Thus, policies based on the notion that having an occupation is directly associated to people's

292 health and life satisfaction might be wrong. In other words, we might need to create activates that

293 target the root of mental illness rather than the symptoms (e.g., unemployment).

294 Importantly, previous research shows that purpose and meaning in life in the general

295 population moderates the relationship between income satisfaction and life satisfaction (Joshanloo,

296 2018). Individuals who believe their lives have meaning and purpose are likely to deemphasize

297 the role of materialistic aspirations, focus more on intrinsic pursuits, and have more mental

298 resources to cope with financial challenges (Joshanloo, 2018). These individuals focus on positive

299 outcomes such as satisfaction with one's life as a whole rather than focusing on particular external

300 factors such as employment. Interviews among individuals with mental illness, for instance,

301 mirror a wish of being accepted by the self and others (i.e., "Being regarded as a whole human

302 being by self and others") and the need of everyday structure, motivating life events, and support

303 from significant others (Blomvist, Sandgren, Carlsson \& Jormfeldt, 2018). In this context, person-

304 centered programs including biopsychosocial services (e.g., well-being coaching), that focus on

305 improving health-related capacities, such as, self-directedness (e.g., self-acceptance, goal-

306 directedness, resourcefulness), cooperativeness (e.g., empathy, helpfulness, social tolerance), and

307 self-transcendence (e.g., flow, meaning in life, spiritual acceptance, unity); are beneficial for

308 different long-term unemployed populations (Cloninger, Granjard, Lester, Lindskär, Rosenberg,

309 Cloninger \& Garcia, 2020). Such biopsychosocial services account for the multidimensional nature

310 of health and provide the evidence-based tools that are needed to alleviate the suffering related to

311 individual's mental illness, and to cope with both unemployment and other challenges of the 21 st

312 century. 
314 Bond GR, Salyers MP, Rollins AL, Rapp CA, Zipple AM. 2004. How evidence-based practices

315 contribute to community integration. Community mental health journal, 40(6), 569-588.

316 Blomqvist M, Ivarsson A, Carlsson IM, Sandgren A, Jormfeldt H. 2018. Health Risks among

317 People with Severe Mental Illness in Psychiatric Outpatient Settings. Issues in Mental Health

318 Nursing, 39(7), 585-591. DOI: 10.1080/01612840.2017.1422200.

319 Blomqvist M, Sandgren A, Carlsson IM, Jormfeldt H. 2018. Enabling healthy living:

320 Experiences of people with severe mental illness in psychiatric outpatient services. International

321 Journal of Mental Health Nursing, 27(1), 236-246. DOI: 10.1111/inm.12313.

322 Cloninger CR. 2004. Feeling good: the science of well-being New York: Oxford University Press.

323 Cloninger KM, Granjard A, Lester N, Lindskär E, Rosenberg P, Cloninger CR, Garcia D.

324 2020. A Randomized Controlled Pilot Study using Mind-Body Interventions among Refugees in

325 Sweden. International Journal of Person Centered Medicine. In press.

326 Corrigan PW, McCracken SG. 2005. Place first, then train: an alternative to the medical model

327 of psychiatric rehabilitation. Social Work, 50(1), 31-39.

328 Diener ED, Emmons RA, Larsen RJ, Griffin S. 1985. The satisfaction with life scale. Journal 329 of personality assessment, 49(1), 71-75.

330 Diener E, Inglehart R, Tay L. 2013. Theory and validity of life satisfaction scales. Social 331 Indicators Research, 112(3), 497-527.

332 Diener E, Lucas RE, Oishi S. 2018. Advances and open questions in the science of subjective 333 well-being. Collabra. Psychology, 4(1). 
334 Dunn EC, Wewiorski NJ, Rogers ES. 2008. The meaning and importance of employment to

335 people in recovery from serious mental illness: results of a qualitative study. Psychiatric

336 rehabilitation journal, 32(1), 59.

337 Garcia D, Siddiqui A. 2009. Adolescents' Affective Temperaments: Life Satisfaction, 338 Interpretation and Memory of events. The Journal of Positive Psychology, 4(2), 155-167.

339 Henwood BF, Derejko KS, Couture J, Padgett DK. 2015. Maslow and mental health recovery:

340 A comparative study of homeless programs for adults with serious mental illness. Administration

341 and Policy in Mental Health and Mental Health Services Research, 42(2), 220-228.

342 Joshanloo M. 2018. Income satisfaction is less predictive of life satisfaction in individuals who

343 believe their lives have meaning or purpose: A 94-nation study. Personality and Individual

344 Differences, 129, 92-94.

345 Lundström S, Ahlström BH, Jormfeldt H, Eriksson H, Skärsäter I. 2017. The Meaning of the

346 Lived Experience of Lifestyle Changes for People with Severe Mental Illness. Issues in Mental

347 Health Nursing, 38(9), 717-725. DOI: 10.1080/01612840.2017.1330909.

348 Lundström S, Jormfeldt H, Hedman Ahlström B, Skärsäter I. 2019. Health-related lifestyle

349 and perceived health among people with severe mental illness: Gender differences and degree of

350 sense of coherence. Archives of Psychiatric Nursing, 33(2), 182-188. DOI:

$351 \quad$ 10.1016/j.apnu.2018.12.002.

352 Marwaha S, Johnson S, Bebbington PE, Angermeyer MC, Brugha TS, Azorin JM, Kilian R,

353 Hansen K, Toumi M. 2007. Rates and correlates of employment in people with schizophrenia in

354 the UK, France and Germany. The British Journal of Psychiatry, 191(1), 30-37.

355 Milner A, Page A, Lamontagne AD. 2014. Cause and effect in studies on unemployment, mental

356 health and suicide: a meta-analytic and conceptual review. Psychological medicine, 44(5), 909 
357 Murphy GC, Athanasou JA. (1999). The effect of unemployment on mental health. Journal of 358 Occupational and organizational Psychology, 72(1), 83-99.

359 National Board of Health and Welfare. 1998. The Reform's first thousand days. Annual report

360 of the Mental Health Reform. Socialstyrelsen: Stockholm.

361 Preacher KJ, Hayes AF. 2008. Asymptotic and resampling strategies for assessing and 362 comparing indirect effects in multiple mediator models. Behavior research methods, 40(3), 879363891.

364 Rohrer JM, Lucas RE. 2020. Causal Effects of Well-being on Health: It's Complicated.

365 PsyArXiv. December 1. doi:10.31234/osf.io/wgbe4.

366 Roberts BW, Harms PD, Caspi A, Moffitt TE. 2007. Can we predict the counterproductive

367 employee? Evidence from a child-to-adult prospective study. Journal of Applied Psychology, 368 92(5), 1427-1436. 


\section{Table 1 (on next page)}

Partially standardized indirect effects of having an occupation on life satisfaction through self-reported physical and psychological health. 
1 Table 1. Partially standardized indirect effects of having an occupation on life satisfaction

2 through self-reported physical and psychological health.

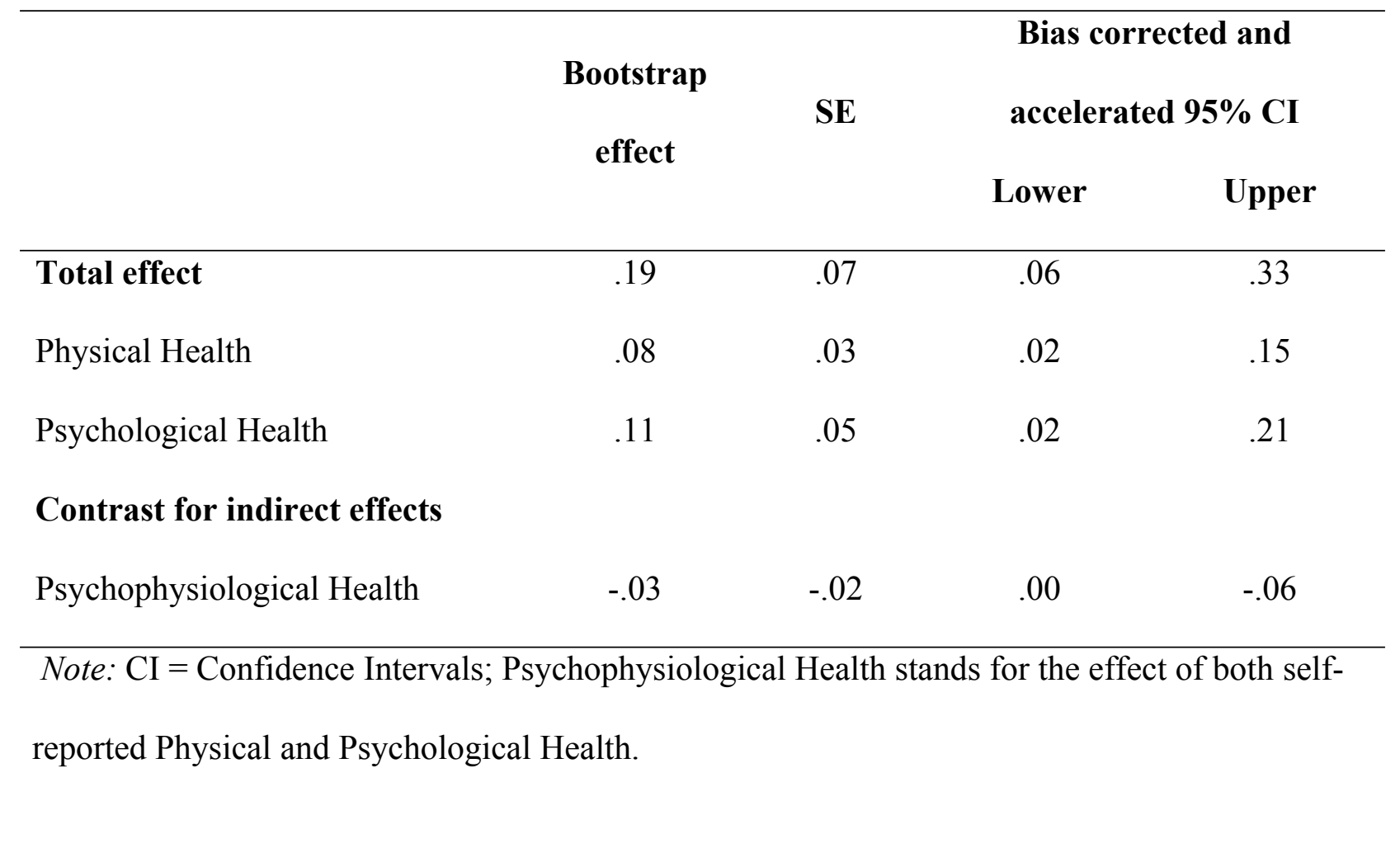


Figure 1

Coefficients representing the effects of occupation on the mediators (i.e., self-reported physical and psychological health) and self-reported life satisfaction.

Note: $* p<.05 ;{ }^{* *} p<.01 ;{ }^{* * *} p<.001 ;$ ns $=$ nonsignificant.

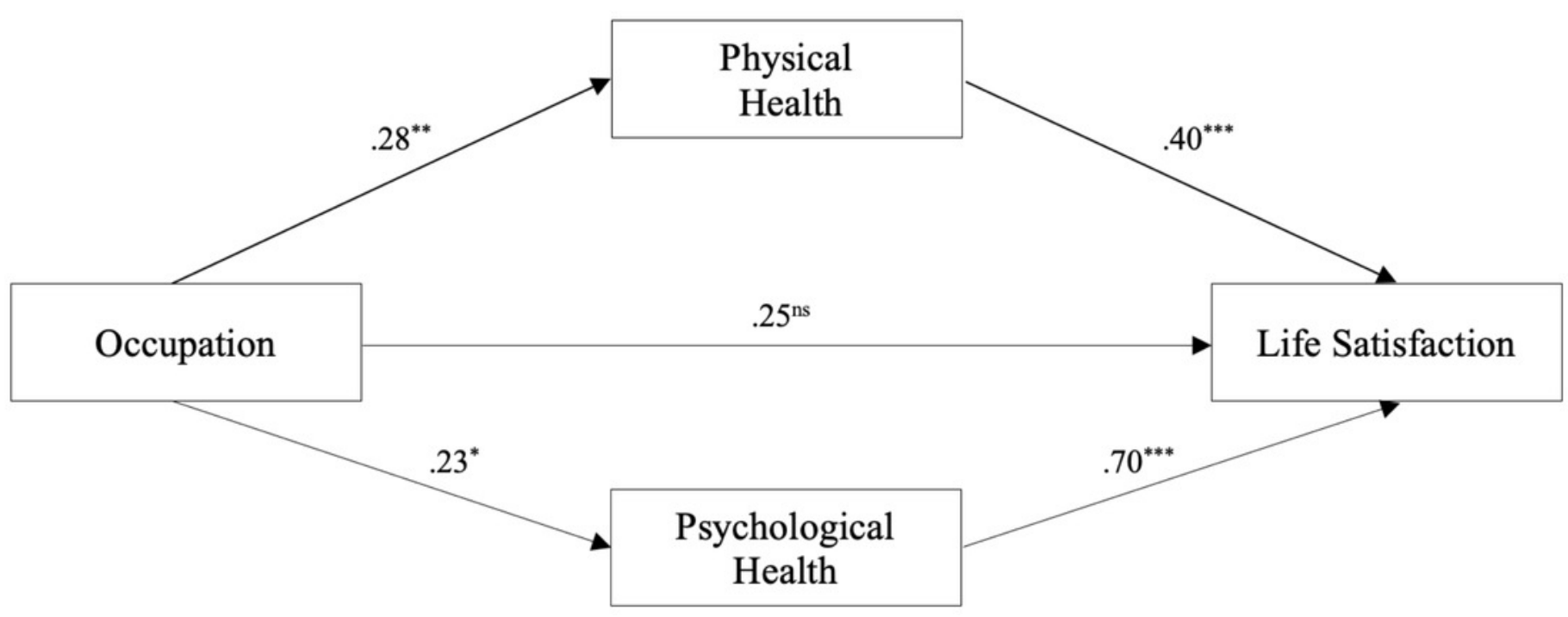

